\title{
BK polyomavirus virus hemorrhagic cystitis following allogeneic bone marrow transplant with haploidentical related donor: case reports from two patients
}

\begin{abstract}
BK virus is well known to be associated with allograft failure in renal transplant recipients due to polyomavirus-associated nephropathy (PVAN). BK viruses are increasingly recognized an important cause of hemorrhagic cystitis during hematopoietic stem cell transplantation (HSCT). Here we describe two patients with acute lymphoblastic leukemia who received a haplo identical match related donor hematopoietic stem cell transplant after myeloablative conditioning and posttransplant cyclophosphamide. They developed cytology proven BK Virus cystitis. Both were treated with Leflunomide. Treatment was effective in alleviating the symptoms temporarily but eventually the symptoms progressed and resulted in mortality of both patients.
\end{abstract}

Keywords: BK virus, cystitis, allogeneic stem cell transplant
Volume 2 Issue 4 - 2017

\author{
Danish Shakeel, Natasha Ali, Mohammad \\ Usman Shaikh, Salman Naseem Adil \\ Department of Oncology, Aga Khan University Hospital, \\ Pakistan
}

Correspondence: Danish Shakeel, Section of Clinical Hematology, Department of Oncology, Aga Khan University Hospital, Pakistan, Stadium road, Karachi, Pakistan, Tel +92 2 3486 I548, +92 21 348645 I I, Email danish.shakeel@aku.edu

Received: August 18, 2017 | Published: October 05, 2017
Abbreviations: PVAN, polyomavirus associated nephropathy; HSCT, hematopoietic stem cell transplantation; PML, progressive multifocal leukoencephalopathy

\section{Introduction}

Hemorrhagic cystitis is a common complication in allogeneic bone marrow transplant recipients. ${ }^{1}$ The association of BK virus cystitis and allogeneic bone marrow transplant was first described two decades ago. ${ }^{2}$ The incidence of hemorrhagic cystitis in allogeneic bone marrow transplant patients is reported up to $70 \%$, while BK viruria after allogeneic bone marrow transplant is detected in 50 to $100 \%$ of the patients. ${ }^{1-6}$ Hemorrhagic cystitis is a cause of significant morbidity following allogeneic bone marrow transplant. Many factors have been implicated in the etiology including the toxic effects of the chemotherapeutic drugs and viral infections. The most common viruses associated with hemorrhagic cystitis in both children and adults are BK virus, cytomegalovirus (CMV) and adenovirus. ${ }^{1,3,7,8}$ Among immunocompromised patients, only two strains of polyomaviruses have been proven to cause disease. Polyomavirus hominis 1 (BK virus) causes cystitis, nephritis and polyomavirus hominis 2 (JC virus) causes multifocal leukoencephalopathy (PML). The prevalence of BK virus increases with intense immunosuppressive therapy and it is probably the most common cause of hemorrhagic cystitis in allogeneic hematopoietic stem cell transplant (allo - HSCT) recipients. ${ }^{9}$ The mainstay of treatment in these patient is reducing the dose of immunosuppressive therapy, bladder irrigation, anti-viral agents and monitoring of BK virus in urine and blood. Up till now only few reports have attributed the role of BK virus in the pathogenesis of hemorrhagic cystitis after allo-HSCT. ${ }^{2,9-11}$ Here we describe two cases of BK virus hemorrhagic cystitis following allogeneic stem cell transplant from a haploidentical match related donor. In the cases discussed below, we used myeloablative-conditioning regimen along with post transplant cyclophosphamide. This resulted in intense immunosuppression leading to reactivation of BK virus. We found that cytology was useful in the diagnosis of BK virus infection in urine. Supportive care along with Leflunomide treatment resulted in improvement of symptoms, however the infection resulted in prolonged hospital stay and significant morbidity.

\section{Case presentation}

\section{Case: I}

A 23-years-old male was diagnosed as precursor B cell acute lymphoblastic leukemia. The prognostic workup showed normal bone marrow karyotyping. He was started on HYPER-CVAD protocol (fractionated cyclophosphamide, vincristine, doxorubicin, and dexamethasone) through which he achieved remission. During the maintenance phase, he developed CNS relapse, which was confirmed by CSF detailed report (DR) and cytology showing 95\% blast cells. Re-induction was attempted through FLAG-IDA protocol (fludarabine, idarubicin, cytarabine) along with intra-thecal chemotherapy, following which, the G-CSF, DR and cytology became negative. Bone marrow examination after induction chemotherapy was in morphological remission. Patient underwent allogeneic bone marrow transplant with blood group matched and sex-matched haplo-indentical related donor. Prior to transplant, patient's CMV IgM antibody and CMV PCR was positive. He therefore received treatment with valgancicylovir. Conditioning regimen included antithymocyte antiglobin (Rabbit-ATG, FRESENIUS) at $10 \mathrm{mg} / \mathrm{kg}$ from day -8 to day -6 , fludarabine $30 \mathrm{mg} / \mathrm{m} 2$ from day -7 to day -2 , low dose total body irradiation (200cGy) once daily from day -5 to day -4 and cyclophosphamide $50 \mathrm{mg} / \mathrm{kg}$ from day -3 to day -2 . For GVHD prophylaxsis cyclophosphamide $50 \mathrm{mg} / \mathrm{kg}$ was given on day +3 , day +4 and mycophenolate mofetil (MMF) along with tacrolimus was started from day +5 . Dose of Tacrolimus was adjusted as required to keep trough level between 10 to $15 \mathrm{ng} / \mathrm{ml}$. Myeloid engraftment occurred on day +19 . On day +27 patient developed burning micturation, dysuria and frank hematuria. Urine DR showed red blood cells of more than 20 per high power field (HPF) and hemoglobin of more 
than 150 per microlitre. Ultrasound revealed, thick walled urinary bladder (approximately $5 \mathrm{~mm}$ ), most likely secondary to cystitis. Patient's coagulation profile was normal, blood and urine cultures were negative. Cytospin preparation of urine revealed inflammatory cells predominantly neutrophils along with urothelial cells. Cells with large, round, homogenous, blue, black inclusion in the nucleus were also identified. Since our laboratory does not perform BK virus $\mathrm{PCR}$, a diagnosis of BK virus cystitis was made through cytology and patient was managed with fluid hydration, bladder irrigation and antiviral therapy (Leflunomide). The treatment, the patient's symptoms improved with negative urine cytology repeated on day +37 and day +56 . However patient presented again on day +100 with hematuria along with transplant related Thrombotic Thrombocytopenic Purpura, MRSA (methicillin-resistant Staphylococcus aureus) bacteremia $\&$ multiorgan failure. He eventually succumbed to his illness on day+109 (Table 1) (Table 2) (Figure 1).

Table I Different diagnostic techniques available for diagnosis of BK virus infection

\begin{tabular}{|c|c|c|c|c|}
\hline Screening method & Positive predictive value (\%) & Negative predictive value (\%) & Sensitivity (\%) & Specificity (\%) \\
\hline Decoy cells $(14,18)$ & 29 & 100 & 25 & 84 \\
\hline BK urine $\mathrm{PCR}(14,18)$ & 40 & 100 & 100 & 78 \\
\hline BK serum $P C R(\mid 4,18)$ & $50-60$ & 100 & 100 & 88 \\
\hline
\end{tabular}

Table 2 Treatment options for BK virus hemorrhagic cystitis $2,7,10,14$

\begin{tabular}{|c|c|c|c|c|}
\hline Name of drug & Class of drug & Mechanism of action & Reported side effects & Effectiveness \\
\hline Leflunomide & Malononitrilamides & $\begin{array}{l}\text { Inhibition of pyrimidine } \\
\text { synthesis \& tyrosine kinases }\end{array}$ & $\begin{array}{l}\text { Rash, alopecia, Thrombocytopenia, } \\
\text { Pancytopenia, Thrombotic } \\
\text { microangiopathy }\end{array}$ & $\begin{array}{l}\text { Doubtful, modest antiviral } \\
\text { effect in vitro }\end{array}$ \\
\hline Cideofovir & Nucleotide analogue & $\begin{array}{l}\text { Inhibition of viral replication } \\
\text { by unknown mechanisms. } \\
\text { Inhibition of DNA polymerase } \\
\text { activity of large T antigen }\end{array}$ & $\begin{array}{l}\text { Headache, Nephrotoxicity, Anterior } \\
\text { uveitis, Neutropenia }\end{array}$ & $\begin{array}{l}\text { Doubtful, mostly case reports } \\
\text { have shown variable results }\end{array}$ \\
\hline Ciprofloxacin & Fluoroqinolone & $\begin{array}{l}\text { Inhibition of polyomavirus } \\
\text { T-antigen helicase activity }\end{array}$ & $\begin{array}{l}\text { Rash, Diarrhea, Nausea, Dizziness, } \\
\text { Headache, Restlessness, Resistance }\end{array}$ & $\begin{array}{l}\text { Doubtful, likely more effective as } \\
\text { prophylactic agent }\end{array}$ \\
\hline $\mathrm{IVIg}$ & Immunomodulatory & $\begin{array}{l}\text { Antibody mediated } \\
\text { neutralization }\end{array}$ & Paradoxical rise in viral load & Doubtful \\
\hline
\end{tabular}
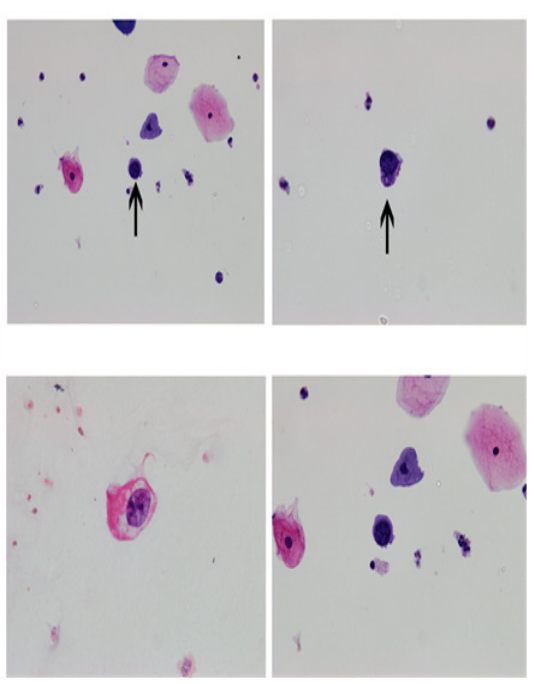

Figure I Panel A and B shows Cytospin preparation (I00x) of urine sample from patient I revealed inflammatory cells predominantly neutrophils along with urothelial cells. Cells with large, round, homogenous, blue, black inclusion in the nucleus were also identified. Panel $C$ and $D$ shows Cytospin preparation (I00x) of urine sample from patient 2 revealed squamous epithelial cells and urothelial cells along with neutrophils, red blood cells, histiocytes and macrophages. Few cells showing large homogenous, even nuclei and BK virus inclusions.

\section{Case: 2}

A 19-years-old male was diagnosed with T cell acute lymphoblastic leukemia and complex bone marrow karyotype. Patient was started on MRC UKALL XII protocol and relapsed after First cycle of consolidation, which was confirmed by bone marrow trephine biopsy. Patient was given re-induction chemotherapy with FLAG-IDA protocol, following which he achieved morphological remission. He underwent allogeneic HSCT with haplo-identical related donor (mother) having minor blood group mismatch. Prior to transplant his CMV serology was positive for IgG. Conditioning regimen included anti-thymocyte antiglobin (Rabbit-ATG, FRESENIUS ) at $10 \mathrm{mg} / \mathrm{kg}$ from day -8 to day -6 , fludarabine $30 \mathrm{mg} / \mathrm{m} 2$ from day -7 to day -2 , low dose total body irradiation (200cGy) once daily from day -5 to day -4 and cyclophosphamide $50 \mathrm{mg} / \mathrm{kg}$ from day -3 to day -2 . GvHD prophylaxis was similar to that of previous case. This patient also received post-transplant cyclophosphamide on day +3 and $+4(50 \mathrm{mg} /$ $\mathrm{kg}$ ). Myeloid engraftment occurred on day +17 . Patient was readmitted on day +50 with gross hematuria and passage of clots during mictuiration. He had persistently decreased hemoglobin while urine DR showed red blood cells of more than 20/HPF, hemoglobin more than 250 per microlitre. Thick-walled urinary bladder (approximately $1.04 \mathrm{~cm}$ ) with large intra luminal blood clot (approximately $9 \times 8 \times 6 \mathrm{~cm})$ was reported on ultrasound. Patient's coagulation profile was normal. His urine culture grew ESBL (Extended spectrum betalactamases) Escherichia coli. Cytospin preparation of urine showed 
squamous epithelial cells and urothelial cells along with neutrophils, red blood cells, histiocytes and macrophages. Few cells showing large homogenous nuclei with inclusions were seen on his cytospin preparation. A diagnosis of BK Virus cystitis was made. Patient was managed with fluid hydration, sensitive intra venous antibiotic, bladder irrigation, anti-viral (Leflunomide) and irradiated blood products transfusion. With treatment hematuria improved but patient expired on day +108 due to secondary graft failure, sepsis and peritonitis.

\section{Discussion}

BK virus was first isolated in 1971 by Gardner and co-workers in the urine sample of a patient who presented with renal failure following kidney transplant. They named the virus after the initials of this patient. BK virus is a non-encapsulated DNA virus that is prevalent in about 90 to $100 \%$ of the population. The virus is transmitted via upper respiratory tract, during the early childhood. Following initial infections the virus can remain latent in the renal urothelium and other organs for entire life. ${ }^{3,5,7}$ Primary infection is asymptomatic or occasionally causes mild self-limiting upper respiratory infection. Disease caused by latent polyomaviruses is typically not seen in the immunocompetent host. During periods of immunosuppression, such as following solid organ or hematopoietic stem cell transplantation, $\mathrm{BK}$ virus reactivation may lead to organ dysfunction. These conditions are characterized by the shedding of viral particles and viral inclusion bearing epithelial cells into the urine and are known as decoy cells. The cells are produced due to massive replication of BK virus in the mucosal layer of urinary bladder resulting in inflammation of bladder wall. Cystitis occurs several weeks after allogeneic bone marrow transplant. Thus examination of urine cytology specimens to search for polyomavirus inclusion bearing cells is an important clinical tool to assess the reactivation of this condition in HSCT recipients. ${ }^{12,13}$ However, cytology has some limitations; such as these decoy cells can be confused with malignant cells and similar cytopathology can result from infections with other viruses e.g. JC virus and adenovirus. The sensitivity of decoy cells is only $25 \%$ with a specificity of $84 \%$. However absence of decoy cells in urine has a negative predictive value of $100 \%$. Therefore, detection of BK virus DNA in the urine by PCR remains the modality of choice with a sensitivity of $100 \%$. Biopsy of renal urothelium is gold standard for detection of BK virus. The diagnosis is based on immunohistochemical stains., ${ }^{2,14}$ A study done by Gore et al. ${ }^{14}$ described various risk factors for the development of BK virus cystitis, the most important being the degree of immunosuppression. Other factors included male gender, old age, rejection episodes, degree of HLA disparity, BK virus serostatus prior to transplant and prolong limb ischemia. ${ }^{2,14} \mathrm{BK}$ virus activation after allogeneic bone marrow transplant is associated with manifestations ranging from asymptomatic viruria to severe hemorrhagic cystitis, ureteral stenosis and interstitial nephritis. Hemorrhagic cystitis is the most prevalent of these complications and occurs in $10-25 \%$ of patients due to the inflammation of bladder wall. Patients present with dysuria, frequency of urination and suprapubic pain. The latter was present in our second patient. The severity of the pain was high on pain scale since he required continuous patient controlled analgesic for relief. Hematuria is variable and the severity of hematuria can be assessed by using a grading system which was proposed by Droller et al. ${ }^{15}$ According to this grading system, grade 0 is no symptoms of bladder irritability or hemorrhage, grade 1 is microscopic hematuria, grade 2 is macroscopic hematuria, grade 3 is macroscopic hematuria with clots and grade 4 is Massive macroscopic hematuria requiring instrumentation for clot evacuation and/or causing urinary obstruction. Both our patients had grade 4 hematuria; the second patient required cystoscopy for clot removal. BK virus hemorrhagic cystitis can also result in renal failure and prolong hospital stay. Both our patients had multiple hospital admissions, which required long stays for the treatment of underlying symptoms. Although it is rarely life threatening BK virus cystitis is associated with significant morbidity. ${ }^{2,15}$ The mortality in our patients occurred due to different causes, but the associated complaint of BK virus cystitis contributed significantly to the morbidity.

In general, treatment of BK virus hemorrhagic cystitis is supportive and includes measures that are directed to control bleeding. Maintaining a platelet count above 50x109/L and a hematocrit of 25\% in patients with $\geq$ grade 2 hematuria can be beneficial. Mild cases resolve spontaneously within few weeks. Clot formation in bladder can occur in severe cases, which may result in obstruction. In these situations, cystoscopy for clot evacuation and possible cauterization may be helpful to preserve renal function. ${ }^{2}$ We carried out the same procedure in our second patient who had persistence of clots in the bladder. The mainstay in the management of BK virus hemorrhagic cystitis is reduction in the immunosuppression. This can be done by either switching tacrolimus to cyclosporine or discontinuing the immunosuppressive agent. Another effective strategy is reduction in the dose of immunosuppressive agents by 25 to $50 \%$, which can be further guided by the trough level of the drug. The aim is to maintain a significantly lower trough level (tacrolimus 3-4ng/ $\mathrm{mL}$ and cyclosporine $50-100 \mathrm{ng} / \mathrm{mL}$, or even less). ${ }^{14}$ Sood et al. ${ }^{16}$ concluded that reduction in immunosuppression alone resulted in the successful resolution of viremia with preservation of renal function and prevention of clinical BKV nephritis and graft loss in significant number of patients. ${ }^{16}$ We stopped immunosuppression in both our patients. The symptoms did not resolve in one while bone marrow suppression occurred in both. Leflunomide belongs to the class of drugs called malononitrilamides. It works by inhibiting protein kinase activity and pyrimidine synthesis. Leflunomide has antiviral activity in vitro against $\mathrm{CMV}$, herpes simplex virus and $\mathrm{BK}$ virus. The drug has been used in allogeneic bone marrow transplant recipients for the treatment of resistant/refractory BK virus infections with variable success. ${ }^{2}$ Both our patients partially responded to this antiviral therapy. Nicole $\mathrm{N}$ et al. ${ }^{17}$ evaluated the role of leflunomide for treatment of biopsy proven BK virus nephropathy. The results showed that $71 \%$ of patients receiving leflunomide (at least $60 \mathrm{mg}$ daily) along with reduction in immunosuppression cleared the virus. ${ }^{17}$

\section{Conclusion}

In conclusion, BK virus infection is a serious and increasingly recognized complication in bone marrow transplant recipients. It is associated with significant morbidity and a prolonged hospital stay. Bone marrow transplant centers should develop a protocol for BK virus surveillance, treatment, and monitoring. Cytological examination of urine is a helpful test for diagnosis of BK virus cystitis, but it has limitations. However newer laboratory based assays may develop in future, making the diagnosis easier. The mainstay of treatment remains careful reduction of immunosuppression, bladder irrigation, blood products transfusion and anti-viral agents. ${ }^{18}$

\section{Acknowledgements}

Dr. Sheema Hasan, Dr. Muhammad Hasan, Ms Siddiqa Maniar, Ms Aisha. 


\section{Conflict of interest}

There is no conflict of interest in this study.

\section{References}

1. Lunde LE, Dasaraju S, Cao Q, et al. Hemorrhagic cystitis after allogeneic hematopoietic cell transplantation: risk factors, graft source, and survival. Bone Marrow Transplant. 2015;50(11):1432-1437.

2. Dropulic LK, Jones RJ. Polyomavirus BK infection in blood and marrow transplant recipients. Bone Marrow Transplant. 2008;41(1):11-18.

3. Silva L De P, Patah PA, Saliba RM, et al. Hemorrhagic cystitis after allogeneic hematopoietic stem cell transplants is the complex result of $\mathrm{BK}$ virus infection, preparative regimen intensity and donor type. Haematologica. 2010;95(7):1183-1190.

4. Held TK, Biel SS, Nitsche A, et al. Treatment of BK virus-associated hemorrhagic cystitis and simultaneous CMV reactivation with cidofovir. Bone Marrow Transplant. 2000;26(3):347-350.

5. Hirsch HH, Randhawa P. BK polyomavirus in solid organ transplantation. Am J Transplant. 2003;Suppl 4:179-188.

6. Bogdanovic G, Priftakis P, Giraud G, et al. Association between a high BK virus load in urine samples of patients with graft-versus-host disease and development of hemorrhagic cystitis after hematopoietic stem cell transplantation. J Clin Microbiol. 2004;42(11):5394-5396.

7. Van Aalderen MC, Heutinck KM, Huisman C, et al. BK virus infection in transplant recipients: clinical manifestations, treatment options and the immune response. Neth J Med. 2012;70(4):172-183.

8. Haines HL, Laskin BL, Goebel J, et al. Blood, and not urine, BK viral load predicts renal outcome in children with hemorrhagic cystitis following hematopoietic stem cell transplantation. Biol Blood Marrow Transplant. 2011;17(10):1512-159.
9. Lekakis LJ, Macrinici V, Baraboutis IG, et al. Bk virus nepropathy after allogenic stem cell transplant: a case report and literature review. Am J Hematol. 2009;84(4):243-246.

10. Hilton R, Tong CY. Antiviral therapy for polyomavirus-associated nephropathy after renal transplantation. $J$ Antimicrob Chemother. 2008;62(5):855-859.

11. Vilchez RA, Kusne S. Molecular and clinical perspectives of polyomaviruses: Emerging evidence of importance in non-kidney transplant populations. Liver Transpl. 2006;12(10):1457-1463.

12. Singh HK, Bubendorf L, Mihatsch MJ, et al. Urine cytology findings of polyomavirus infections. Adv Exp Med Biol. 2006;577:201-212.

13. Nickeleit V, Mihatsch MJ. Polyomavirus nephropathy in native kidneys and renal allografts: an update on an escalating threat. Transpl Int. 2006;19(12):960-973.

14. Sawinski D, Goral S. BK virus infection: an update on diagnosis and treatment. Nephrol Dial Transplant. 2015;30(2):209-217.

15. Droller MJ, Saral R, Santos G. Prevention of cyclophosphamide-induced hemorrhagic cystitis. Urology. 1982;20(3):256-258.

16. Sood P, Senanayake S, Sujeet K, et al. Management and outcome of BK viremia in renal transplant recipients: a prospective single-center study. Transplantation. 2016;94(8):814-821.

17. Nesselhauf N, Strutt J, Bastani B. Evaluation of leflunomide for the treatment of BK viremia and biopsy proven BK nephropathy; a single center experience. J Nephropathol. 2016;5(1):34-37.

18. Nickeleit V, Klimkait T, Binet IF, et al. Testing for polyomavirus bk dna to identify renal-allograft recipients with viral nephropathy. $N$ Engl $J$ Med. 2000;342(18):1309-1315. 